\title{
Three-phase PWM Sinusoidal Current Rectifier with Power Conditioning Capability
}

\author{
M. I. Milanés Montero, E. Romero Cadaval, V. M. Miñambres Marcos, M. A. Guerrero Martínez \\ Power Electrical \& Electronic Systems Research Group. School of Industrial Engineering. \\ Department of Electrical, Electronic and Automation Engineering. University of Extremadura. \\ Avda. de Elvás s/n. 06006. Badajoz (Spain). \\ Phone +34924 289600. Fax +34 924289601 . \\ e-mail:milanes@unex.es,eromero@unex.es,vminmar@unex.es,mguerrmar@peandes.unex.es
}

\begin{abstract}
This paper presents a PWM three-phase rectifier controlled to demand a sinusoidal source current in phase with the positive-sequence fundamental source voltage, providing unity displacement power factor. The operation of the rectifier is controlled so that in case of a nonlinear load connected to the grid, the power converter also operates as an active power filter, improving the global power quality. Experimental results with a laboratory prototype are included to test the control strategy.
\end{abstract}

\section{INTRODUCTION}

The widely use of power electronic converters has caused a proliferation of non-linear loads injecting harmonic, unbalanced and reactive current components into the electrical power system. These current components, due to the voltage drop at the source impedance, deteriorate the power quality of the system, causing harmonics and imbalance in the voltage at the point of common coupling (PCC) and a low power factor [1].

On the one hand, the reduction or elimination of these undesirable current components can be achieved by using compensation equipments installed at the PCC, typically active power filters [1]-[5]. These power filters are usually Voltage Source Inverters (VSI) operating as currentcontrolled sources [3].

On the other hand, most of the nonlinear loads that are noncontrolled single-phase or three-phase loads or diode rectifiers and Controlled Thyristor Rectifiers (TCR) to supply power to DC railways, take part in ac/dc/ac converters in three-phase inductor motor drives applications, etc. In recent years, single-phase PWM rectifiers [6][7] and three-phase PWM rectifiers [8]-[10] have been developed to replace these converters, trying to reduce the harmonic consumption by improving the power factor and allowing a reversible power flow [6].

This paper proposes a novel operation mode for a threephase PWM rectifier, providing capability to behave also as an active power filter so it reduces the harmonic distortion and imbalance produced by near nonlinear loads. This operation mode can be achieved by taking advantage of the topology used in the PWM rectifier, a VSI, which constitutes the typical inverter topology employed in an Active Power Filter (APF). The simple proposed control strategy of the VSI will be able to operate the converter in three different operation modes: as a PWM Sinusoidal Current Rectifier (SCR), as an APF or as a Hybrid System (PWM SCR and APF).

Firstly, the three operation modes are explained. Afterwards the control strategy of the converter and the tracking technique to generate the switching signals are detailed. Then, experimental results with a laboratory prototype are included, testing the operation modes and the control strategy. Conclusions regarding to the use of the different operation modes with the same converter are finally delivered.

\section{Power Stage. Operation Modes}

The electric system used in this paper is the one shown in Fig. 1. A three-phase four-wire system is proposed. A neutralpointed-clamped VSI is connected to the PCC by means of filter inductors $L_{A F}$. The mid-point of the dc bus is connected directly to the neutral conductor. The loads of the system are:

- a resistive load, $R_{L 1}$, connected to the dc part of the VSI and

- a group of nonlinear loads, comprising a diode rectifier with resistive load $R_{L 2}$, connected to the PCC.

The switches $S_{1}$ and $S_{2}$ allow selecting the operation modes, which are detailed in the following sections.

\section{A. PWM Sinusoidal Current Rectifier}

The equipment operates as a PWM SCR when there are no nonlinear loads connected to the PCC, but a dc load is connected to the dc side of the rectifier. In the scheme proposed in Fig. 1, this situation can be studied if the switch $S_{2}$ is open (OFF) and the switch $S_{1}$ is closed $(\mathrm{ON})$. Therefore a nonlinear load (a non-controlled rectifier supplying a resistive load, $R L_{1}$ ) will be connected to the PCC.

This proposed load would demand a source current with high harmonic content, but when the converter is controlled to act as a PWM SCR, it will behave as a linear load demanding a sinusoidal current with unity displacement power factor. Besides, the VSI allows to regulate the DC bus voltage and to supply more power than a diode rectifier.

With this operation mode the system acts as a customergenerated disturbances suppressor. 


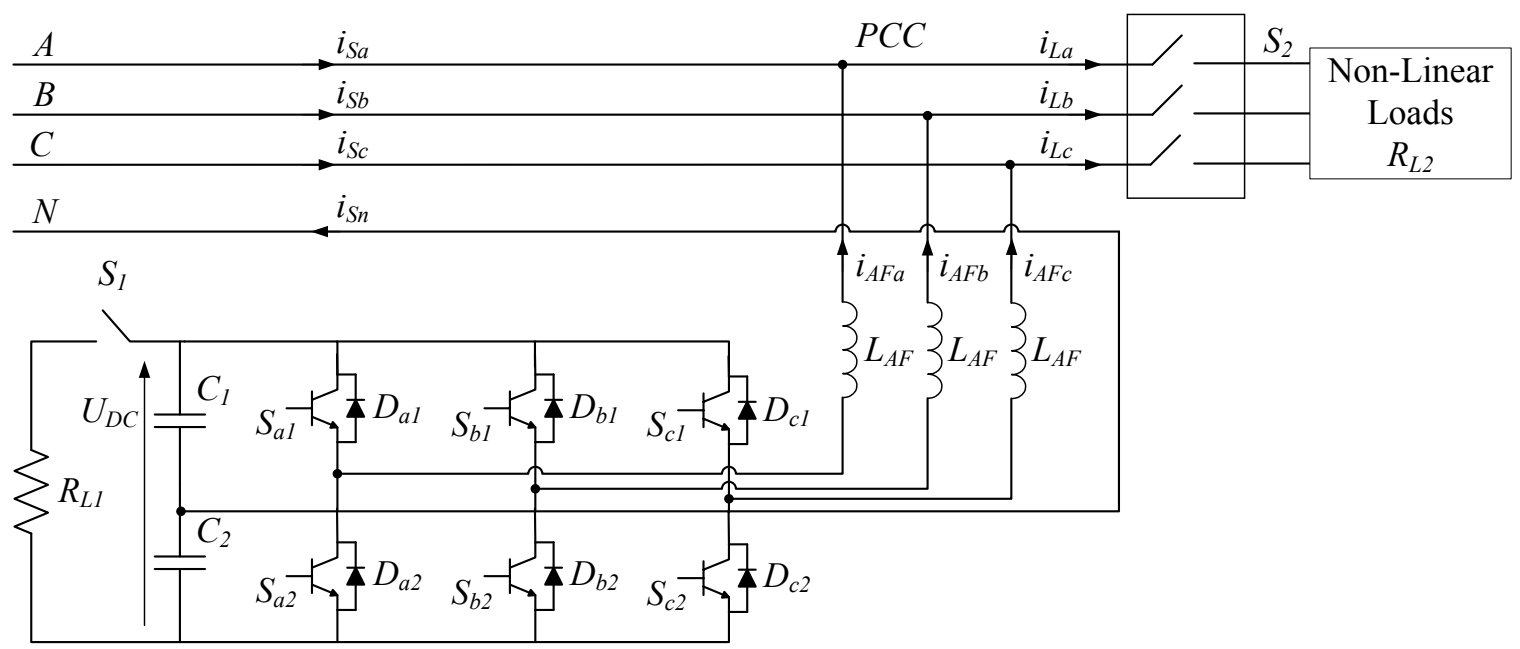

Fig. 1. Three-phase four-wire system with non-linear load and three-phase PWM rectifier with resistive load.

\section{B. Active Power Filter}

In order to make this converter more valuable, if the $\mathrm{dc}$ load is not connected to the rectifier, this equipment could work as an active power filter, reducing the disturbed currents injected by a nonlinear load and improving the displacement power factor of the system. This situation can be studied with the system proposed in Fig. 1 if the switch $S_{1}$ is open (OFF) and the switch $S_{2}$ is closed (ON). Therefore the nonlinear load $R_{L 2}$ will be connected to the PCC.

With this operation mode the converter is controlled so that it injects the necessary compensating current to avoid the harmonics and imbalance in the load current, achieving sinusoidal and balanced source currents.

\section{Hybrid System: PWM Rectifier and APF}

The most general and useful operation mode of the converter is when it acts as a hybrid system, working as a PWM SCR and an APF. This operation mode allows reducing the disturbances caused by the dc load but, at the same time, allows reducing the disturbances produced by other loads connected at the same PCC. In the system proposed in Fig. 1, this case can be studied if $S_{2}$ is closed $(\mathrm{ON})$ and $S_{1}$ is closed $(\mathrm{ON})$. Therefore, the Hybrid System will work as an APF and as a PWM Rectifier.

The converter operates as a hybrid system providing all the advantages described for the previous operation modes at the same time. It is controlled to inject the necessary current so that the source currents will be sinusoidal and balanced with unity displacement power factor at the PCC. The DC bus voltage will reach the adequate reference value to support both functions.

\section{CONTROL STRATEGY}

The general control strategy proposed for the converter is a simple Sinusoidal Source Current (SSC) control strategy. The objective of this strategy is that the constant power demanded by the load (the dc load and/or the non-linear load) will be delivered by the source as positive-sequence fundamental active power, eliminating harmonics and unbalance components in the source current.

In the most general case, regarding to a three-phase fourwire system with harmonics and imbalance, this strategy tries the source current to be proportional to the positive-sequence fundamental component of the PCC voltage. For this reason the method has also been called Fundamental Voltage Synchronization (FVS) [11]. With this criterion the displacement power factor compensation and also the harmonic and unbalanced components correction are delivered.

The reference source current vector $\mathbf{i}_{S r e f}$ for a system like the one shown in Fig. 1 is:

$$
\mathbf{i}_{\text {Sref }}=K \mathbf{u}_{P C C}^{1+} \text {. }
$$

where $\mathbf{u}_{P C C}^{1+}$ is the positive-sequence fundamental voltage and $K$ is the equivalent conductance of the nonlinear load, the VSI and the dc load together; which behaves as a resistor for the positive-sequence fundamental component while as an open-circuit for the rest of components. Its value is determined trying to null the error between the measured dc voltage $U_{D C \text {, meas }}$ and a reference value $U_{D C \text {,ref }}$, employing a proportional $P$ or Proportional-Integral $P I$ controller with a transfer function $k_{c}(\mathrm{~s})$ :

$$
K=\left(U_{D C, \text { ref }}-U_{D C, \text { meas }}\right) k_{c}(s) \text {. }
$$

Operating in (1) and (2), the final expression for the reference source current will be

$$
\mathbf{i}_{\text {Sref }}=\left(U_{D C, \text { ref }}-U_{D C, \text { meas }}\right) k_{c}(s) \mathbf{u}_{P C C}^{1+},
$$

so that sinusoidal and balanced source currents in phase with positive-sequence fundamental voltages are secured.

The block scheme of the control strategy in case of using a PI controller is shown in Fig. 2, where the ASRF block is an Autoadjustable Synchronous Reference Frame [12] developed for extracting the positive-sequence fundamental component of the PCC voltages in three-phase systems. The block diagram of the ASRF is shown in Fig. 3. It is a modified Phase-locked-loop system which operates with high accuracy under harmonic and unbalanced voltages. 


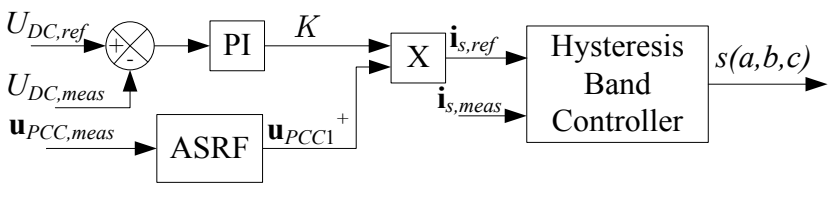

Fig. 2. Control Block Scheme.

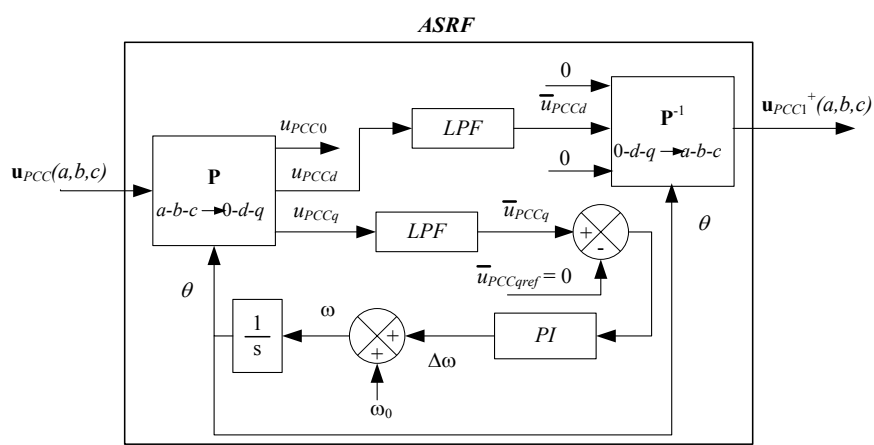

Fig. 3. Block diagram of the ASRF

The advantages of this strategy are:

- The algorithm is very simple, making its implementation in a real-time processor very easy.

- It is a general algorithm, which attains an adequate operation of the converter independently of the operation mode.

- The load current is not measured for extracting the reference current, so the number of sensors is reduced comparing with classical control strategies for APF [11].

\section{TRACKING TECHNIQUE}

The tracking technique should secure that the reference compensating current is tracked by the VSI current, $i_{A F}$, with the minimum error. In a switching period, $T_{S}$, it is satisfied that (Fig. 1):

$$
\Delta i_{S}+\Delta i_{A F}=\Delta i_{L} .
$$

where $i_{L}$ is the load current.

As the switching frequency of the VSI is high (about 10 or $20 \mathrm{kHz}$ ), the load current can be considered approximately constant in $T_{S}$. Imposing this condition in (4), the next expression is obtained

$$
\Delta i_{A F}=i_{\text {AFref }}-i_{\text {AFmeas }} \approx-\Delta i_{S}=-\left(i_{\text {sref }}-i_{\text {smeas }}\right) .
$$

where $i_{\text {AFref }}$ is the VSI reference current, $i_{\text {AFmeas }}$ is the VSI measured current, $i_{\text {sref }}$ is the source reference current and $i_{\text {smeas }}$ is the source measured current.

So the tracking error in the VSI current can be obtained from the reference source current calculated by the control strategy and its measured value, what implies that the measurement of the source current is enough for the tracking technique (see Fig. 2). Finally using a current controller, such as dead beat or hysteresis controllers, the switching signals for the inverter, $s(a, b, c)$, are generated [13][14].

The tracking technique in Fig. 2 is a non-modulated method, which directly generates the switching signals taking into account the hysteresis band of the controller. It is based in nonlinear feedback loops with comparators. The switching signals change when the tracking error exceeds a predetermined tolerance band.

\section{POSITIVE-SEQUENCE FUNDAMENTAL COMPONENT EXTRACTION}

The block diagram of the ASRF [12] which allows calculating the positive-sequence fundamental phase to neutral PCC voltages from their instantaneous values measurements is detailed in Fig. 3. The three voltages are transformed from $a-b-c$ to $0-d-q$ coordinates, using the Clark transformation:

$$
\mathbf{P}=\sqrt{\frac{2}{3}\left[\begin{array}{ccc}
\frac{1}{\sqrt{2}} & \frac{1}{\sqrt{2}} & \frac{1}{\sqrt{2}} \\
\cos \theta & \cos \left(\theta-\frac{2 \pi}{3}\right) & \cos \left(\theta+\frac{2 \pi}{3}\right) \\
-\sin \theta & -\sin \left(\theta-\frac{2 \pi}{3}\right) & -\sin \left(\theta+\frac{2 \pi}{3}\right)
\end{array}\right],},
$$

where $\mathbf{P}$ is the transformation matrix which satisfies: $\|\mathbf{P}\|=1 ; \mathbf{P}^{-1}=\mathbf{P}^{T}$, and $\theta$ is the angle formed by the synchronous reference frame and the $\alpha-\beta$ frame.

The PCC voltage will be, in the most general case, distorted and/or unbalanced. From a reference frame rotating at $\omega_{1}^{+}$, the $\mathbf{u}_{P C C}$ projection over the $d$ axis will be $u_{P C C d}=\bar{u}_{P C C d}+\tilde{u}_{P C C d}$, where de de term will correspond to the direct fundamental component of the PCC voltage. On the other hand, the projection of the vector over the $q$ axis will be formed by two terms, $u_{P C C q}=\bar{u}_{P C C q}+\tilde{u}_{P C C q}$, being the dc term the quadrature fundamental component of the PCC voltage. In this situation $\omega=\omega_{1}^{+}$. But if the reference frame is perfectly adjusted with the vector $\mathbf{u}_{P C C 1}^{+}$, what means the $d$ axis will be in phase with this vector, it will result that:

- the mean value of the direct component will be equal to the modulus of the positive-sequence fundamental component of the PCC voltage $\bar{u}_{P C C d}=\left\|\mathbf{u}_{P C C 1}^{+}\right\|$, and

- the mean value of the quadrature component will be null, $\bar{u}_{P C C q}=0$.

The value $\bar{u}_{P C C q}$ obtained in each control cycle is compared with the reference, $\bar{u}_{P C C q}=0$, and the error goes into a PI controller whose output is the necessary $\Delta \omega$ for getting the synchronization. When the error will be null, $\Delta \omega$ will be constant as well as the velocity of the reference system $\omega=\omega_{1}^{+}$, performing a linear variation in the angle $\theta=\theta_{1}^{+}$ between 0 and $2 \pi$. Just at that moment the ASRF will have 
autoadjusted with the positive-sequence fundamental component.

For improving the convergence in the adjustment, an initial value for the pulsation of the reference system is assigned, $\omega_{0}$, which will be a frequency closed or equal to $50 \mathrm{~Hz}$ (optimal value for utilities with nominal frequencies of 50 or $60 \mathrm{~Hz}$ ).

From the coordinate $\bar{u}_{P C C d}$, imposing a null value for the $q$ and 0 components, the inverse coordinates change is carried out for obtaining the positive-sequence fundamental component of the input. When the synchronization will be performed, $\bar{u}_{P C C d}=\left\|\mathbf{u}_{P C C 1}^{+}\right\|$and the ASRF output will be the vector $\mathbf{u}_{P C C 1}^{+}(a, b, c$,$) .$

The dc components are extracted using low-pass filters with rapid response, such as Butterworth filters. Looking for a compromise between robustness and fastness, second-order filters with a cut-off frequency of $13 \mathrm{~Hz}$ has been selected.

\section{EXPERIMENTAL RESULTS}

The experimental laboratory prototype of the converter is a neutral-pointed-clamped VSI as the one shown in Fig. 1. The values of all the elements for the experimental tests are shown in TABLE I. The dSpace has been the hardware platform utilized to carry out the experimental test.

The measured signals needed are seven:

- the three-phase voltage at the PCC,

- the three-phase source current and

- the dc voltage.

The results are shown in Fig. 4, Fig. 5 and Fig. 6, where the variables displayed in the oscilloscope are in the same order. From top to bottom it is shown for the phase $a$ :

- the PCC voltage, $u_{P C C a}$,

- the nonlinear load current, $i_{L a}$,

- the source current, $i_{s a}$ and

- the compensating currents, $i_{A F a}$.

The vertical scale is $100 \mathrm{~V}$ per division for voltage and $2 \mathrm{~A}$ per division for currents in all figures.

The operation mode as a PWM SCR is shown in Fig. 4, the performance as an Active Power Filter (Fig. 5) and, finally, Fig. 6 shows the converter acting as a Hybrid System.

In Fig. 4(a) one can observe the source current when the switches of the VSI are OFF. The voltages at the PCC are sinusoidal and balanced. There is no nonlinear load, $i_{L a}$, so the source current is opposite to the PWM SCR current. Once the converter is ON, (Fig. 4(b)) the source current of the converter is perfectly sinusoidal and balanced, with unity displacement power factor.

TABLE I

VALUES OF THE COMPENSATOR PARAMETERS

\begin{tabular}{|c|c|c|c|c|c|c|}
\hline $\boldsymbol{U}_{\mathrm{FN}}(\mathbf{V})$ & $\boldsymbol{L}_{\mathrm{FA}}(\mathbf{m H})$ & $\boldsymbol{C}_{\mathbf{1}}(\mathbf{m F})$ & $\boldsymbol{C}_{\mathbf{2}}(\mathbf{m F})$ & $\boldsymbol{R}_{\mathrm{L} 1}(\mathbf{\Omega})$ & $\boldsymbol{R}_{\mathrm{L} 2}(\mathbf{\Omega})$ & $\boldsymbol{U}_{\mathrm{DC}, \text { ref }}(\mathrm{V})$ \\
\hline 25 & 28 & 20 & 10 & 48 & 200 & 80 \\
\hline
\end{tabular}

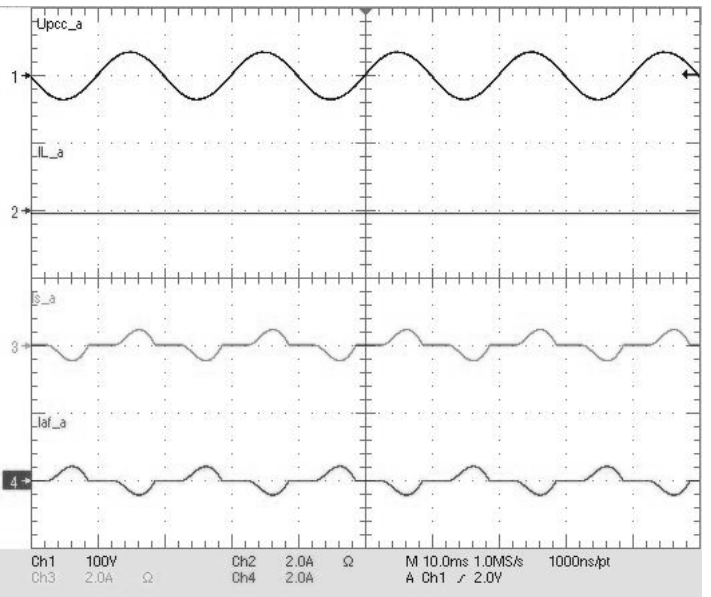

(a)

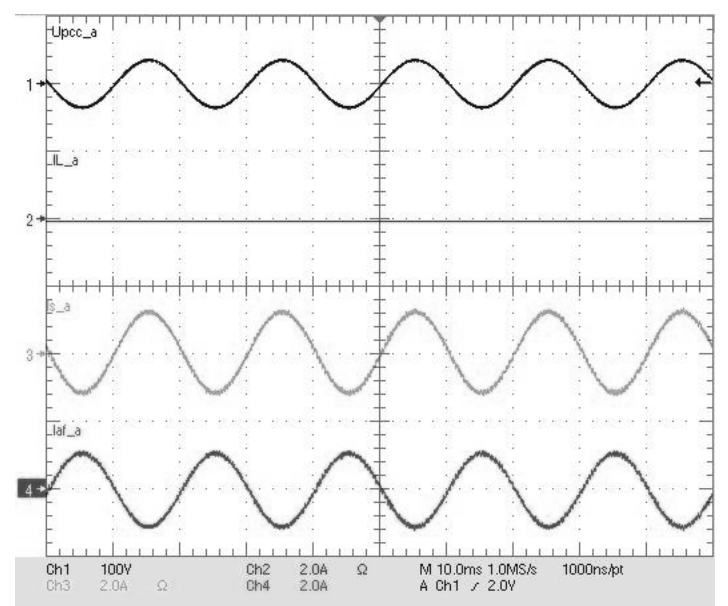

(b)

Fig. 4. Experimental results when the converter operates as a PWM Sinusoidal Current Rectifier: (a) OFF Mode and (b) ON Mode. Vertical scale: voltage $100 \mathrm{~V} / \mathrm{div}$, currents $2 \mathrm{~A} / \mathrm{div}$.

Horizontal scale: $10 \mathrm{~ms} /$ div.

In Fig. 5(a) the experimental results when the converter acts as an APF, but with the switching devices in OFF Mode, are displayed. Then, in Fig. 5(b) the results when the converter is $\mathrm{ON}$ are shown. One can notice sinusoidal source currents with low THD.

Finally, in Fig. 6, the operation of the VSI as a Hybrid System making tasks related to a PWM SCR and an APF at the same time is shown. In Fig. 6(a) experimental results are displayed when the converter is still OFF. One can notice the source current waveform, due to the addition of the nonlinear load $i_{L}$ and the load provided by the PWM SCR, when the switches of the converter are OFF. When the converter is controlled using the described control strategy, the source current becomes sinusoidal. The compensating current has a higher Root Mean Square (RMS) value, since in this test the operation of the VSI has the double task of demanding a sinusoidal current from the PWM SCR and compensating the harmonic current drawn by the nonlinear load. 


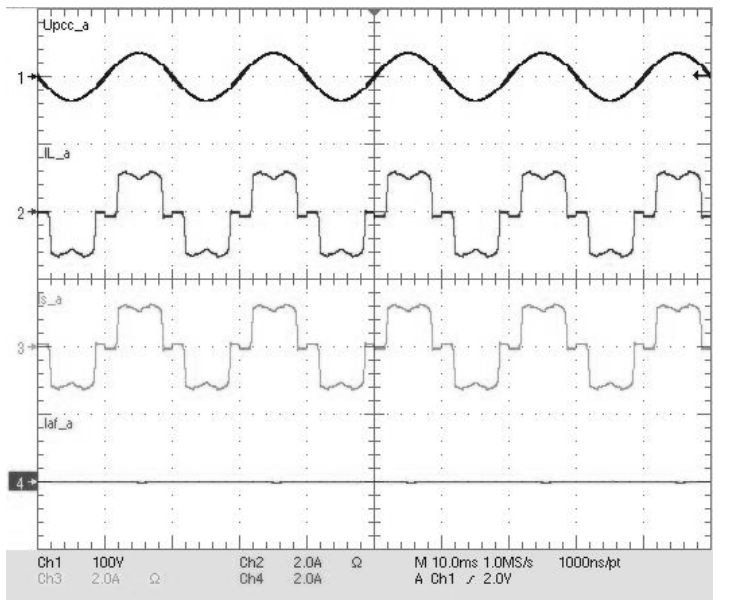

(a)

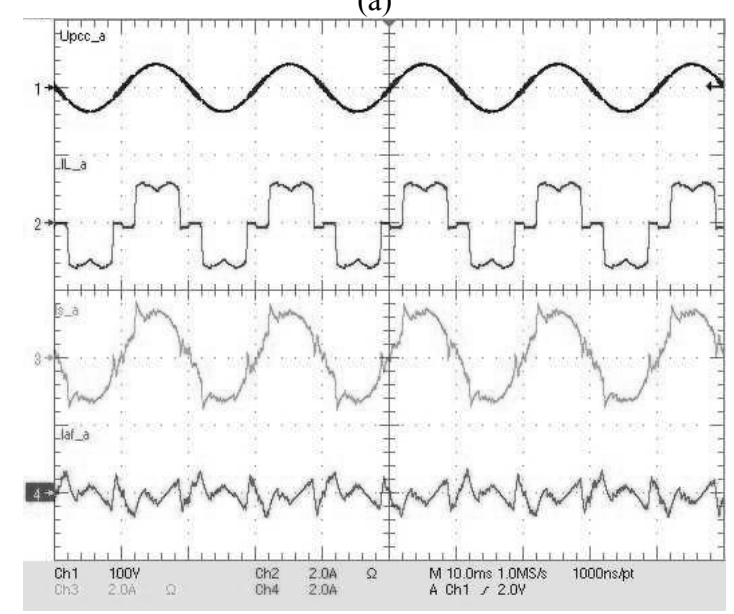

(b)

Fig. 5. Experimental results when the converter operates as an APF compensating the currents injected by a non-linear load: (a) OFF Mode and (b) ON Mode.

Vertical scale: voltage $100 \mathrm{~V} / \mathrm{div}$, currents $2 \mathrm{~A} / \mathrm{div}$.

Horizontal scale: $10 \mathrm{~ms} / \mathrm{div}$.

\section{CONCLUSIONS}

In this paper a three-phase PWM Sinusoidal Current Rectifier with three different operation modes has been reported. A general-purpose control strategy for the VSI has been developed. This control strategy is very simple and valid for all the operation modes. An additional advantage of the proposed strategy is that the control stage, based on the source current measurement, guarantees the use of minimum measurements. Experimental results have been carried out to test the operation modes of the converter and validate the control strategy.

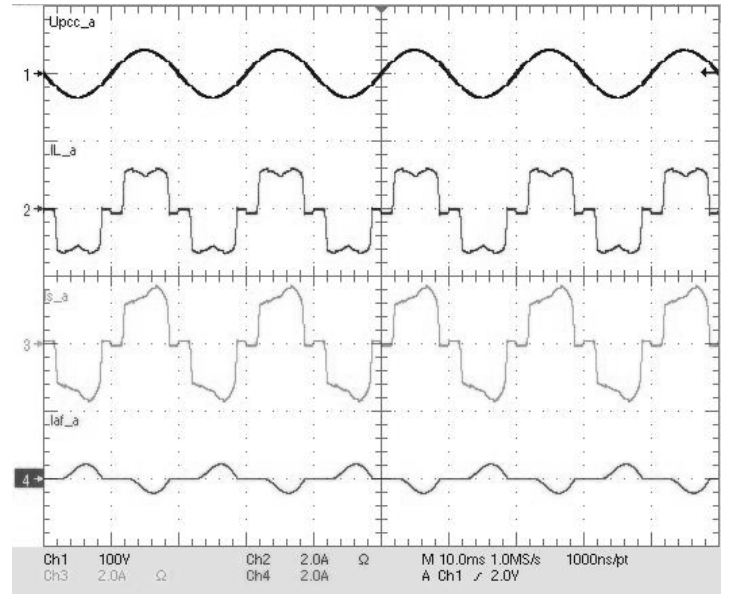

(a)

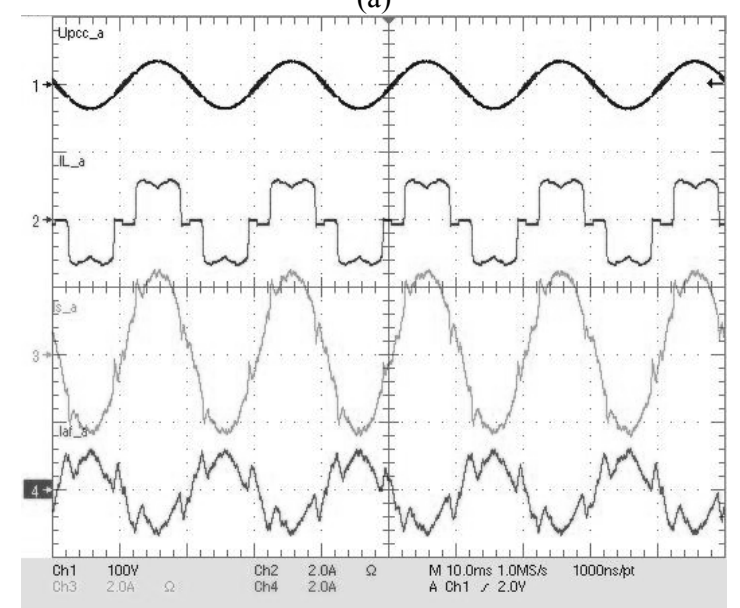

(b)

Fig. 6. Experimental results when the converter oerates as a Hybrid Equipment (PWM rectifier+APF): (a) OFF Mode and (b) ON Mode. Vertical scale: voltage $100 \mathrm{~V} /$ div, currents $2 \mathrm{~A} / \mathrm{div}$. Horizontal scale: $10 \mathrm{~ms} /$ div.

\section{REFERENCES}

[1] H. Akagi, "New Trends in Active Filters for Power Conditioning", IEEE Trans. Industry Applications, vol. 32, no. 6, pp. 1312-1322. Nov/Dec. 1996.

[2] B. Singh, K. Al-Haddad and A. Chandra, "A review of Active Filters for Power Quality Improvement", IEEE Trans. Industrial Electronics, vol. 46, no. 5, pp. 960-971. Oct. 1999.

[3] F. Barrero, S. Martínez, F. Yeves, F. Mur and P.M. Martínez, "Universal and reconfigurable to UPS active power filter for line conditioning", IEEE Trans. Power Delivery, vol. 18, no. 1, pp. 319-325. Jan. 2003.

[4] Don A. G. Pedder, Andrew D. Brown J. Neil Ross, y Alan C. Williams. "A Parallel-Connected Active Filter for the Reduction of Supply Current Distortion", IEEE Transactions on Industrial Electronics, Vol. 47, № 5, pp. 1108-1117, 2000. 
[5] Sato Yukihiko, Takeshi Kawase, Masamitsu Akiyama, y Teruo Kataoka. "A control strategy for general-purpose active filters based on voltage detection". IEEE Transactions on Industry Applications, vol. 36, pp. 1405-1412, Sept. 2000.

[6] D.-C. Lee, Y.-S. Kim. "Control of Single-Phase to Three-Phase $\mathrm{AC} / \mathrm{DC} / \mathrm{AC} \mathrm{PWM}$ Converters for Induction Motor Drives". IEEE Transactions on Industrial Electronics, Vol. 54, № 2, pp. 797 - 804, 2007.

[7] K. Thiyagarajah, V. T. Ranganathan, B.S. Ramakrishna, "A High Switching Frequency IGBT PWM Rectifier/Inverter System for AC Motor Drives Operating from Single Phase Supply", IEEE Transactions on Power Electronics, Vol. 6, N ${ }^{\circ}$ 4, pp. 576-584, 1991.

[8] P. Rastogi, N. Mohan, C. P. Henze. "Three-phase sinusoidal current rectifier with zero-current switching". IEEE Transactions on Power Electronics, Vol. 10, No 6, pp. 753-759, 1995.

[9] K. Zhou, D. Wang, "Digital Repetitive Controlled Three-Phase PWM Rectifier", IEEE Transactions on Power Electronics, Vol. 18, No 1, pp. 309-316, 2003.

[10] C. Liu, B. Wu, Y. Li, S. Wei. "A Novel Three-phase PWM Rectifier/Inverter without Capacitor in DC-link". Int. Conf. on Electrical Machines and Systems, ICEMS 2007, pp. 50-53. 2007.

[11] M. I. Milanés-Montero, E. Romero-Cadaval, A. Rico-de Marcos, V. Miñambres-Marcos and F. Barrero-González, “A Novel Fundamental Voltage Synchronization Control Strategy for Shunt Single-phase and Three-phase Active Power Filters". Power Electronics Specialists Conference, 2008. PESC 2008. IEEE, pp. 2191 - 2196, 2008.

[12] M. I. Milanés-Montero, E. Romero-Cadaval, A. Rico-de Marcos, V. Miñambres-Marcos and F. Barrero-González, "Novel Method for Synchronization to Disturbed Three-phase and Single-phase Systems", in Proc. ISIE 2007, pp. 860-865. 2007.

[13] E. Romero, M. Milanés, F. Barrero. "A modified Switching Signal generation Technique to Minimize the RMS Tracking Error In active Filters". IEEE Trans. Ind. Applications., vol. 20, no. 5, Sept. 2005.

[14] Manjusha Dawande and Gopal K. Dubey. "Bang-Bang Current Control with Predecided Switching Frequency for Switch-Mode Rectifiers", IEEE Transactions on Industrial Electronics, Vol. 46, No 1, pp. 61-66, 1999. 